\title{
Anatomy teaching - a passion or a profession
}

\author{
*Dr Latika Arora, \\ Associate Professor, Anatomy Deptt Santosh Medical College and Hospital
}

\begin{abstract}
Anatomy forms one of the basic sciences to cultivate academic knowledge and clinical experience. A multidisciplinary approach is used to teach anatomy using both classical and modern approach. Such integration of various methods of teaching enhances the student's knowledge of anatomy and their clinical experience. Also teachers should be sensitive to various problems faced by students relating to their experience with cadaver, improving their conceptual knowledge and making anatomy learning a enjoyable experience
\end{abstract}

Human anatomy is an important course in the education of medical professionals. The curriculum of anatomy course and different resources used for anatomy teaching helps in better understanding of the subject. According to rules laid down by MCI 1997 the undergraduate student should know about preventive, curative and rehabilitative aspect of medicine ${ }^{1}$. With new approach towards medical education, focus is more on holistic approach of anatomy teaching.

Over the past few decades teaching of anatomy by dissection has decreased. Due to opening of many new medical schools and lack of cadaver, anatomical dissection has been on decline. Though there is no significant report about the poor performance of students in their exams, but there is concern about relative lack of anatomical knowledge of students for clinical purpose.

\section{Dissection as a method of teaching}

Dissection is a basic technique for undergraduate students to understand the basic concepts of anatomy. The effectiveness of teaching human topographical anatomy to medical students been recognized for centuries ${ }^{2}$. A way to improve student's learning is to change the method of teaching and allow students to take active participation. Oh CS etal ${ }^{3}$ have advised digital reporting of dissection by the students. They asked a group of students to make a digital report of dissection and submit it to the authorities. This lead to active teamwork of students in dissection.

Dissection also encourages students to confront the topics of death and dying. Many cases of students fainting or getting hysterical have been reported when they first come in contact with cadaver. A small number of students are not able to cope up with psychological aspect of working with cadaver and are severely stressed for a long time ${ }^{4}$. Students are unable to express fear and ask for support. For this reason every medical school should organize seminar and counseling to help students deal with cadaver and anatomical preparation.

\section{Intolerance to formalin}

Active learning of anatomy by dissection has many benefits. Most of the anatomy teachers complain about student's lack of interest in dissection. One of the reasons reported by Naz $\mathrm{S}$ et $\mathrm{al}^{5}$ is aversion to formaldehyde smell. Formalin is a colorless irritant which gives out a pungent formaldehyde vapors and is widely used in anatomy for preservation of cadaver. Students usually report symptoms of burning eyes, shortness of bresth, headache and skin irritation on exposure to formalin. As preventive measure students should be encouraged to use gloves and laboratory coats. Dissection halls should be well ventilated. Esima $R$ etal ${ }^{6}$ have suggested thiel embalming as an alternative to formalin fixing. Thiel fixed specimens have more life visual and haptic properties but is more expensive. There are many restrictions for it's use for student's dissection in facilities with limited storage space and air circulation. Moreover thiel fixed specimens are not suitable for histological preparations and thus more research work is required on thiel fixed specimens.

\section{Simultaneous sketching with dissection}

The students actively involved in dissection have reported dissection as an active learning process in comparison to didactic lectures on gross anatomy. Simultaneous sketching with dissection is a more interactive learning technique for anatomy teaching. With every table in dissection hall a small blackboard should be provided to teachers to encourage learning by sketching.

With the advent of powerpoint presentation, animation techniques and video imaging, sketching has taken a back seat in anatomy teaching. Sketching helps students understand spatial relationship between complex objects ${ }^{7}$. Therefore newer techniques of anatomy teaching should be integrated with sketching. 


\section{3D anatomy learning}

It is also essential for medical students to learn anatomy in three dimension. In medical schools anatomical dissection should be integrated with diagnostic computed tomography radiology. Cadavers should be scanned and then students should consult CT images during dissection to have a better understanding.

\section{References}

[1]. Salient features of regulations on graduate medical education. Available at http://mciindia .org $\backslash$ know $\backslash$ rules_mbbs.htm( accessed on 8 august 2014)

[2]. Team based learning methods in teaching topographical anatomy by dissection. Burqess AW, Ramsey Stewart G, May J and Mellis C. Anz J Surg 2012; 82(6); 457-60[pubmed]

[3]. Digital report in an anatomy laboratory : a new method for team based dissection, reporting and evaluation. Oh CS, Kim KJ, Ching E and Choi HJ. Surg RadiolAnat 2014( accessed on 24 Aug 2014)[pubmed]

[4]. Psychosocial aspects of donation and dissection course. An extra curricular program with the objective of assisting students confront issues surrounding gross anatomy lab. Weyers S, Noack T and Rekhamper. GMS Z Med Ausbild 2014 [pubmed] ( free PMC article)

[5]. Perceptions of cadaveric dissection in anatomy teaching. Naz S,Nazir G, IramS, Mohammad M,Umair, Qari IH,Mohammad S. J Ayub Med Coll Abottabad 2011;23(3);145-8

[6]. From formalin to theil embalming: What changes? One anatomy department's experiences. Eisma R, Lamb C and Soames RW. Clin Anat 2013; 26(5): 564-71

[7]. 3D modeling of branching vessels from anatomical sketches : towards a new interactive teaching of anatomy . Interactive virtual blackboard. Palombi O, Pihuit A and Cani MP. Surg Radiol Anat 2011;33(7); 631-6 